\title{
Correction to: Unusual Mechanism of Myocardial Infarction in Prosthetic Valve Endocarditis
}

Armindo Jreige Júnior, Felipe Bezerra Martins de Oliveira, Larissa Lucas Schloicka, Fernando Antibas Atik, and Claudio Ribeiro da Cunha

Correction to:

R. M. S. Almeida, F. B. Jatene (eds.),

Cardiovascular Surgery,

https://doi.org/10.1007/978-3-319-57084-6_16

This chapter was inadvertently published with incorrect order of Given name and Family name for the author "Armindo Jreige Júnior" and the name has been updated to correct order -

Given Name: Armindo

Family Name: Jreige Júnior

The updated version of this chapter can be found at https://doi.org/10.1007/978-3-319-57084-6_16 